\title{
Commentary: Are the proposed benefits of melatonin-rich foods too hard to swallow?
}

\author{
Marcello Iriti ${ }^{1 *}$ and Elena Maria Varoni ${ }^{2}$ \\ ${ }^{1}$ Department of Agricultural and Environmental Sciences, Milan State University, Milan, Italy, ${ }^{2}$ Department of Biomedical, \\ Surgical and Dental Sciences, Milan State University, Milan, Italy
}

Keywords: biokinetics, bioactive compounds, Mediterranean diet, nutraceuticals, functional food

\section{A commentary on}

Are the proposed benefits of melatonin-rich foods too hard to swallow?

by Kennaway DJ. Crit Rev Food Sci Nutr (2015). doi: 10.1080/10408398.2014.962686

Even if the discovery of melatonin in plants dates back to $1995(1,2)$, in the past decade, the topic of melatonin in plant foods has been largely investigated (3-5). Certainly, the detection of melatonin in grapevine (6), an important food plant, promoted the studies in this new and exciting research field. Noteworthy, it was also suggested that dietary melatonin may be regarded as a bioactive phytochemical, similar to polyphenols, as well as a component of the traditional Mediterranean diet (7-9).

In this context, the recent article by Kennaway, entitled "Are the proposed benefits of melatoninrich foods too hard to swallow?" (10), appeared in Critical Reviews in Food Science and Nutrition, really astonished and disappointed us. In his review, the author criticized the studies investigating the measurement of blood and urine melatonin after the intake of foods containing this indoleamine. The author suggested that the claimed increases in circulating melatonin are not consistent with the amount of the dietary melatonin ingested, stating that "Studies reporting the appearance of melatonin in blood and its metabolites in urine following ingestion of melatonin-rich foods appear to be flawed." We want to use this paper to highlight the urgency of high-quality studies on this topic, rather than to disapprove the currently available results.

Indeed, we think that some data and issues emphasized in this article can be, instead, discussed from a different perspective. Such perspective largely depends on the poor-quality of methodology applied to perform the existing studies on blood melatonin $(11,12)$. None of these clinical trials achieve the high standard of quality required by the evidence-based medicine approach, necessary for drug efficacy assessment as well as for phytochemical research (13). No randomized, placebocontrolled, double-blinded clinical trial is available, so far, on dietary melatonin. The use of placebo, in particular, appears to be undoubtedly one of the major problems to overcome, being that food is a very complex matrix where a plethora of active ingredients can act in concert (as melatonin and polyphenols, another important group of bioactive phytochemicals) (8).

This paucity of studies on efficacy of foods rich in melatonin largely hinders the achievement of reliable conclusions in answering the Kennaway's question: "Are the proposed benefits of melatonin-rich foods too hard to swallow?" However, the author, lapidary, concludes: "While there may be health benefits of ingestion of certain foods it is difficult to accept that they are due to their melatonin content." The only data used in the review to support this sentence are based on criticism of (very few) biokinetics results on blood melatonin, rather than findings on the beneficial effects of dietary melatonin on health (as mentioned before, to date still miss-

Front. Nutr. 3:2.

doi: 10.3389/fnut.2016.00002 ing). It is also interesting to note as the biokinetics data on blood melatonin provided by the 
author as "reference" are based on studies where melatonin was administered as pure compound. It is well known, instead, how phytochemical bioavailability strictly depends on the complexity of food matrix, consisting of plant cell-wall polysaccharides, hydrosoluble and non-hydrosoluble fibers, and other inert components.

In addition, the paradigm of dietary melatonin is somewhat limiting while our knowledge on food tryptophan derivatives and indoleamines is now more and more increasing. In the last decade, our experience mainly focused on grape and wine. We demonstrated that a number of melatonin isomers are present in red wine and, probably, in other plant foods, as well as a high amount of tryptophan and tryptophan ethylester, a putative tryptophan donor (14-17). In this view, melatonin can also be produced from tryptophan locally by the gastrointestinal tract and, then, released in the bloodstream, thus confounding the levels of the food melatonin really absorbed. In fact, enteroendocrine (or enterochromaffin) cells can synthesize serotonin and melatonin from tryptophan and/or its derivatives, which are contained in the plant foods (18). Nonetheless, serotonin is abundantly contained in these foods (19) and may be directly converted into melatonin within the gut. Noteworthy, melatonin produced in the gastrointestinal tract represents a major pool of extrapineal melatonin, reaching much higher levels than in the pineal gland (20).

With regard to methodology, another hypothesis, as also suggested by the author, is that indoleamines different from melatonin, mainly its isomers, may generate misinterpretation of the results because of their cross-reactivity during the analysis. The latter has been mainly based on the enzyme-linked

\section{REFERENCES}

1. Dubbels R, Reiter RJ, Klenke E, Goebel A, Schnakenberg E, Ehlers C, et al. Melatonin in edible plants identified by radioimmunoassay and by high performance liquid chromatography-mass spectrometry. J Pineal Res (1995) 18:28-31. doi:10.1111/j.1600-079X.1995.tb00136.x

2. Hattori A, Migitaka H, Iigo M, Itoh M, Yamamoto K, Ohtani-Kaneko R, et al. Identification of melatonin in plants and its effects on plasma melatonin levels and binding to melatonin receptors in vertebrates. Biochem Mol Biol Int (1995) 35:627-34.

3. Arnao MB, Hernández-Ruiz J. Functions of melatonin in plants: a review. $J$ Pineal Res (2015) 59:133-50. doi:10.1111/jpi.12253

4. Reiter RJ, Tan DX, Zhou Z, Cruz MHC, Fuentes-Broto L, Galano A. Phytomelatonin: assisting plants to survive and thrive. Molecules (2015) 20:7396-437. doi:10.3390/molecules20047396

5. Tan DX. Melatonin and plants. J Exp Bot (2015) 66:625-6. doi:10.1093/jxb/ eru523

6. Iriti M, Rossoni M, Faoro F. Melatonin content in grape: myth or panacea? J Sci Food Agric (2006) 86:1432-8. doi:10.1002/jsfa.2537

7. Iriti M, Varoni EM, Vitalini S. Melatonin in Mediterranean traditional diets. J Pineal Res (2010) 49:101-5. doi:10.1111/j.1600-079X.2010.00777.x

8. Iriti M, Varoni EM. Melatonin in Mediterranean diet, a new perspective. J Sci Food Agric (2015) 95:2355-9. doi:10.1002/jsfa.7051

9. Iriti M, Varoni EM. The good health of Bacchus: melatonin in grapes, the unveiled myth. LWT Food Sci Technol (2016) 65:758-61. doi:10.1016/j. lwt.2015.09.010

10. Kennaway DJ. Are the proposed benefits of melatonin-rich foods too hard to swallow? Crit Rev Food Sci Nutr (2015). doi:10.1080/10408398.2014.9 62686 immunosorbent assay (ELISA), which is the sole technique, so far, used to determine blood melatonin after food intake $(11,12)$. We strongly encourage, in the future, the use of more reliable techniques, such as liquid chromatography coupled to mass spectroscopy (LC-MS), to assess unequivocally the amount of melatonin.

Furthermore, the production of microbial melatonin by the colonic microbiota represents another fascinating perspective to further comprehend the measured levels of melatonin after food intake. Even if no study is now available on this topic, the gut microflora may embody an alternative source of melatonin, possibly synthesized by some types of bacteria, which deserves to be investigated (20). The development of a specific LC-MS/ MS method could shed significantly more light on the origin: if stable-isotope-labeled precursors are applied, the labeling pattern of melatonin and its sulfate could indicate the contribution of the different biosynthetic pathways.

We think that more scientific in human evidences should be collected before any judgment is expressed, similarly to what occurred and is still ongoing about the health-promoting effects of dietary polyphenols. We recommend more high-level studies, rather than considering "flawed" currently available data. These latter, although preliminary, can be considered a good starting point to grow knowledge on this relatively novel food component and ascertain, besides its real concentrations in blood, the effects of such levels on health.

\section{AUTHOR CONTRIBUTIONS}

$\mathrm{MI}$ and EV conceived the commentary and wrote the manuscript.

11. Maldonado MD, Moreno H, Calvo JR. Melatonin present in beer contributes to increase the levels of melatonin and antioxidant capacity of the human serum. Clin Nutr (2009) 28:188-91. doi:10.1016/j.clnu.2009.02.001

12. Sae-Teaw M, Johns J, Johns NP, Subongkot S. Serum melatonin levels and antioxidant capacities after consumption of pineapple, orange, or banana by healthy male volunteers. J Pineal Res (2013) 55:58-64. doi:10.1111/ jpi. 12025

13. Varoni E, Lodi G, Iriti M. Efficacy behind activity - phytotherapeutics are not different from pharmaceuticals. Pharm Biol (2014) 53:404-6. doi:10.3109/13 880209.2014.923000

14. Vitalini S, Gardana C, Simonetti P, Fico G, Iriti M. Melatonin, melatonin isomers and stilbenes in Italian traditional grape products and their antiradical capacity. J Pineal Res (2013) 54:322-33. doi:10.1111/jpi.12028

15. Gardana C, Iriti M, Stuknytė M, De Noni I, Simonetti P. "Melatonin isomer" in wine is not an isomer of the melatonin but tryptophan-ethylester. J Pineal Res (2014) 57:435-41. doi:10.1111/jpi.12183

16. Iriti M, Vigentini I. Tryptophan-ethylester, the false (unveiled) melatonin isomer in red wine. Int J Tryptophan Res (2015) 8:27-9. doi:10.4137/IJTR.S22450

17. Vigentini I, Gardana C, Fracassetti D, Gabrielli M, Foschino R, Simonetti $\mathrm{P}$, et al. Yeast contribution to melatonin, melatonin isomers and tryptophan ethyl ester during alcoholic fermentation of grape musts. J Pineal Res (2015) 58:388-96. doi:10.1111/jpi.12223

18. Konturek SJ, Konturek PC, Brzozowski T, Bubenik GA. Role of melatonin in upper gastrointestinal tract. J Physiol Pharmacol (2007) 58(Suppl 6):23-52.

19. Huang X, Mazza G. Application of LC and LC-MS to the analysis of melatonin and serotonin in edible plants. Crit Rev Food Sci Nutr (2011) 51:269-84. doi:1 $0.1080 / 10408398.2010 .529193$

20. Acuña-Castroviejo D, Escames G, Venegas C, Díaz-Casado ME, LimaCabello E, López LC, et al. Extrapineal melatonin: sources, regulation, and 
potential functions. Cell Mol Life Sci (2014) 71:2997-3025. doi:10.1007/ s00018-014-1579-2

Conflict of Interest Statement: The authors declare that the research was conducted in the absence of any commercial or financial relationships that could be construed as a potential conflict of interest.
Copyright $\odot 2016$ Iriti and Varoni. This is an open-access article distributed under the terms of the Creative Commons Attribution License (CC BY). The use, distribution or reproduction in other forums is permitted, provided the original author(s) or licensor are credited and that the original publication in this journal is cited, in accordance with accepted academic practice. No use, distribution or reproduction is permitted which does not comply with these terms. 